researchers, however it is well established that there can be long delays in the translation of knowledge into practice. The objective of this work is to accelerate the impact and dissemination of evidence based falls prevention research through use of ICT technology, European wide collaboration and campaigning.

Methods This presentation will describe effective strategies using ICT technologies, free access resources, media tools and context specific targeted campaigning to raise awareness of best evidence in falls prevention and to facilitate widespread implementation. ProFouND consortium partners and multi-sectorial stakeholders based throughout the regions (118) were invited to take part in a series of dissemination activities.

Resources and information can be found at ProFouND.eu.com Results In this paper, we contribute to the narrative evidencebase by outlining key benefits, challenges and mechanisms that may enable effective implementation of research evidence relevant to other contexts. Following a comprehensive survey of all partners and associate partners (including EIP AHA), engagement from the 12 participating countries was largely achieved, particularly in areas with dedicated personnel. This resulted in widespread dissemination through public engagement events, television, radio and multi-sectorial stakeholders, health websites, social media and NGO uptake and coverage.

Conclusions An understanding of methods to increase effective dissemination and implementation of robust evidence can ensure that effort is put to best use to improve public health knowledge in areas such as falls prevention. With relatively small investments of time and resources we conclude that ICT technologies for the dissemination of research are worthwhile and offer great potential in raising awareness, widening access and increasing engagement with best evidence falls prevention resources.

\section{RISK FACTORS FOR HIP FRACTURES DUE TO FALLS IN THE ELDERLY DURING ONE YEAR 2014/15 IN KIEV}

${ }^{1}$ Vladyslav Ashrafutdinov, ${ }^{2}$ Johan Lund. ${ }^{1}$ University of Oslo; ${ }^{2}$ Norwegian Directorate of Health, Oslo

\subsection{6/injuryprev-2016-042156.964}

Background Hip fracture is one of the most serious injuries that can be experienced in the elderly: $20-30 \%$ will die in the following year and many more will experience significant functional loss. Moreover hip fracture implies long-lasting great financial expenditure for patient's treatment. $90 \%$ of hip fractures are caused by falls. This study seems to be the first investigation of risk factors for hip fractures in Ukraine.

Methods Study was carried out in two Kiev hospitals. A sample of 50 patients $55+$ treated from February 2014 to January 2015 was collected, 45 were in -depth interviewed about their hip fracture experience. Study design was qualitative, retrospective and prospective, case exploratory. Observational method and in-depth interviewing were applied.

Results Most common causation of fall leading to hip fracture was stumbling/tripping over different barriers. Indoors risk factors were thresholds, loose wire, broken interior elements. Outdoors risk factors were pets, broken asphalt, and some architectural forms.
In wintertime the main risk factor was slippery surface. Other accident types were pushing, loss of balance, colliding with other person.

Conclusions Numerous environmental risk factors were identified, the most common were icy/wet surface and physical barriers like thresholds, pets and loose wire. Slipping has significance in wintertime, while stumbling/tripping, pushing and loss of balance can occur throughout the year. A set of recommendations was proposed.

\section{ANALYSIS OF VISION AND RELATED RISK FACTORS AMONG THE FALLS OF ELDERLY IN COMMUNITIES OF BEIJING CITY, CHINA}

${ }^{1}$ ZHANG Xin-yi, ${ }^{2}$ MA Yin-nan" ${ }^{\#},{ }^{1}$ IAN Ya-fei, ${ }^{1} \underline{L}$ Li-ping. ${ }^{1}$ Injury Prevention Research Centre, Shantou University Medical College, Shantou 515041,China; ${ }^{2}$ Beijing Research Centre of Urban System Engineering, Beijing 100035, China

\subsection{6/injuryprev-2016-042156.965}

Background To investigate the incidence and characteristics of falls in senior citizens at xicheng district community in Beijing, analyse the relationship among falls incidence of the elderly, vision and related falls risk factors, and provide guidance for the elderly on fall prevention and intervention.

Methods The survey covered all the 7 communities on xinjiekou street at xicheng district in Beijing, 1082 elderly people who meet the requirements of over 60 years old were surveyed by systematic sampling method and 1082 investigation forms were received (response rate was 100\%), and 1034 effective questionnaires were obtained (effective rate was 95.6\%), including 399 men (38.6\%) and 635 women (61.4\%). Presenting visual acuity (VA), slit-lamp examination, direct fundus ophthalmoscope, stereopsis test and colour vision examination were measured at 141 old people.

Bivariate analysis was performed by Chi-square test, and multiple analysis was performed by Logistic regression.

Results In 1034 of the elderly, 167 people experienced 189 times falls in the past 2 years and incidence rate of falls among the elderly was $16.2 \%$.It was higher in women $(18.0 \%)$ than in men $(13.3 \%)$, there were significant difference in fall incidence rate between women and men $(\mathrm{P}=0.047)$. The proportions of 141 old people examining vision $<1.0$ was $56 \%$, and proportion losing Stereo vision completely was $7.8 \%$. Eye disease inspection results showed that cataract $(91.5 \%)$ and macular degeneration $(33.3 \%)$ were the major eye disease in old people. According to our results, the risk factors of falls were cataract $(\mathrm{P}=0.004$, $\mathrm{OR}=1.727,95 \% \mathrm{CI}: 1.187 \sim 2.512)$, glaucoma $(\mathrm{P}=0.028$, $\mathrm{OR}=2.507$, occupation $(\mathrm{P}=0.041)$, dizziness $(\mathrm{P}=0.001$, $\mathrm{OR}=2.663,95 \% \mathrm{CI}: 1.503 \sim 4.614)$, other body disease $(\mathrm{P}=0.003, \mathrm{OR}=1.801,95 \% \mathrm{CI}: 1.217 \sim 2.666), 95 \% \mathrm{CI}:$ $1.105 \sim 5.684)$. when compared to the age group from 60 to 64 years old, 70 to 79 years old elderly have more falls risk $(\mathrm{P}=0.002)$.

Conclusions The incidence rate of falls is high in the elderly of Beijing urban communities, and cataract and glaucoma lead to decreased vision are the risk factors of falls. 